OPEN ACCESS

Edited by:

Surya Kant,

Grains Innovation Park, Horsham,

Australia

Reviewed by:

Mamoru Okamoto,

University of Adelaide, Australia Raffaella Balestrini,

Italian National Research Council, Italy

Jagesh Kumar Tiwari,

Central Potato Research Institute

(ICAR), India

${ }^{*}$ Correspondence:

Younès Dellero

younes.dellero@inrae.fr

Specialty section:

This article was submitted to

Plant Physiology,

a section of the journal

Frontiers in Plant Science

Received: 03 September 2020

Accepted: 03 November 2020

Published: 30 November 2020

Citation:

Dellero Y (2020) Manipulating Amino Acid Metabolism to Improve Crop Nitrogen Use Efficiency for a

Sustainable Agriculture.

Front. Plant Sci. 11:602548.

doi: $10.3389 /$ fpls.2020.602548

\section{Manipulating Amino Acid Metabolism to Improve Crop Nitrogen Use Efficiency for a Sustainable Agriculture}

\author{
Younès Dellero* \\ IGEPP, INRAE, Institut Agro, Univ Rennes, Le Rheu, France
}

In a context of a growing worldwide food demand coupled to the need to develop a sustainable agriculture, it is crucial to improve crop nitrogen use efficiency (NUE) while reducing field $\mathrm{N}$ inputs. Classical genetic approaches based on natural allelic variations existing within crops have led to the discovery of quantitative trait loci controlling NUE under low nitrogen conditions; however, the identification of candidate genes from mapping studies is still challenging. Amino acid metabolism is the cornerstone of plant $\mathrm{N}$ management, which involves $\mathrm{N}$ uptake, assimilation, and remobilization efficiencies, and it is finely regulated during acclimation to low $\mathrm{N}$ conditions and other abiotic stresses. Over the last two decades, biotechnological engineering of amino acid metabolism has led to promising results for the improvement of crop NUE, and more recently under low $\mathrm{N}$ conditions. This review summarizes current work carried out in crops and provides perspectives on the identification of new candidate genes and future strategies for crop improvement.

Keywords: source-sink relationships, senescence, amino acid, catabolism, assimilation, transport, nitrogen use efficiency (NUE), crop plant

\section{INTRODUCTION}

More than half of the world's population are fed by crops grown with the addition of synthetic nitrogen (N) fertilizers (Zhang et al., 2015). This supply of $\mathrm{N}$ coupled to other essential nutrients has allowed farmers to increase crop production per unit to meet food demand over the last century. However, nearly $50 \%$ of $\mathrm{N}$ fertilizers applied to the field are not used by crops, independently of world region or crop type. This $\mathrm{N}$ surplus has led to disastrous consequences that threaten the sustainability of agricultural production systems. The application of inorganic $\mathrm{N}$ fertilizers in agricultural areas has largely contributed to the increase of soil acidification, gaseous ammonia emissions in the atmosphere, and nitrate levels in our water resources, with dangerous consequences for human health (Behera et al., 2013; Ward et al., 2018). Therefore, it is crucial to improve crop $\mathrm{N}$ use efficiency (NUE) while reducing $\mathrm{N}$ inputs to the field to meet the growing food demand in a sustainable agriculture context. Plant NUE can be defined as the maximal quantity of seeds or biomass (depending on downstream applications) obtained from a defined amount of $\mathrm{N}$ supplied to plants (Xu et al., 2012). Plant NUE comprises the capacity to take up $\mathrm{N}$ from the soil ( $\mathrm{N}$ uptake efficiency, NUpE) and the capacity to utilize this $\mathrm{N}$ efficiently within the plant to produce the harvested product 
(N utilization efficiency, NUtE). NUtE integrates the capacity to assimilate inorganic $\mathrm{N}$ into carbon $(\mathrm{C})$ skeletons $(\mathrm{N}$ assimilation efficiency, NAE) to produce amino acids (AA) and subsequently essential $\mathrm{N}$-containing molecules (proteins, DNA, RNA, chlorophylls, etc.) and the capacity to remobilize assimilated $\mathrm{N}$ from source-to-sink tissues ( $\mathrm{N}$ remobilization efficiency, NRE; Avice and Etienne, 2014). AA metabolism is the cornerstone of plant $\mathrm{N}$ management since it is actively involved in both NUpE and NUtE through AA and protein biosynthesis, senescence-induced degradation of proteins into AAs, and overall source-to-sink AA transport (Tegeder and MasclauxDaubresse, 2018). Comparison of pool sizes between free AAs and AAs in proteins nicely highlights the fine regulation exerted on AA metabolism to support primary metabolism and plant growth (Hildebrandt et al., 2015). Regulation of AA metabolism also plays an active role during acclimation to low $\mathrm{N}$ conditions and other abiotic stresses including heat, cold, dark, drought, and salt (Kant et al., 2011; Hildebrandt, 2018). Therefore, AA metabolism is an interesting target for the improvement of crop NUE in both sustainable agriculture and future climate change contexts. The use of classical genetic approaches based on natural allelic variations existing within plant species and varieties for this purpose have already been undertaken for rice, maize, wheat, barley, and rapeseed (Han et al., 2015; Bouchet et al., 2016). While some quantitative trait loci (QTL) associated with crop NUE under low N conditions have been found, the identification of determinant candidate genes from mapping studies is still a challenge. Over the two last decades, genetic engineering of AA metabolism has given some promising results with respect to the improvement of crop NUE and more recently under low $\mathrm{N}$ conditions. This review summarizes current and promising future targets for the genetic manipulation of AA metabolism in crops with respect to NUE improvement and tolerance to low $\mathrm{N}$ conditions and other abiotic stresses.

\section{AMMONIA ASSIMILATION}

Nitrogen is first taken up from the soil by plant roots in the form of nitrate ions, ammonium ions, and AAs. Prior to be assimilated, nitrate is reduced to nitrite in the cytosol, which is then reduced to ammonium in plastids. This reduction can occur either directly in the roots or in the leaves after a transport step via the xylem (Masclaux-Daubresse et al., 2010; Yoneyama and Suzuki, 2019). In plants, the major ammonia assimilation route is via the glutamine synthetase/ glutamate:2-oxoglutarate aminotransferase (GS/GOGAT) cycle; however, asparagine synthetase (ASN) and glutamate dehydrogenase (GDH) can also participate depending on plant status (Masclaux-Daubresse et al., 2010).

\section{Glutamine Synthetase/Glutamate:2- Oxoglutarate Aminotransferase Cycle}

GS catalyzes the ATP-dependent condensation of ammonia and Glu to form Gln. Then, GOGAT transfers the amide group of Gln to 2-oxoglutarate to produce two molecules of Glu with the consumption of reducing power (either as reduced ferredoxin or as NADH). There are two types of GS enzyme in plants: GS1 and GS2. In Arabidopsis, a single gene (GLN2) encodes the chloroplast-localized GS2 isoform that is mainly responsible for ammonia assimilation in photosynthetic tissues and for the reassimilation of photorespiratory ammonia released by the activity of mitochondrial glycine decarboxylase complex (GDC; Wallsgrove et al., 1987). In Arabidopsis, GS1 is encoded by five genes (GLN1-1 to GLN-5). While GS1 enzymes are located to the cytosol, their expression patterns in leaves, roots, and phloem companion cells can significantly vary depending on environmental conditions. GS1 enzymes play a key role in roots for ammonium assimilation and in vascular tissues for $\mathrm{N}$ reallocation as Gln to sink tissues during senescence (Martin et al., 2006; Lothier et al., 2011; Avila-Ospina et al., 2015). There are also two types of GOGAT in plants: Ferredoxin-GOGAT (Fd-GOGAT), present in leaf chloroplasts and encoded by two genes in Arabidopsis (GLU1 and GLU2) and NADH-GOGAT, present in plastids of phloem companion cells and encoded by a single gene in Arabidopsis (GLT1; Suzuki and Knaff, 2005).

GS1 has attracted attention for many years as a potential target for the improvement of crop NUE, due to its central role in ammonia assimilation in roots and $\mathrm{N}$ remobilization during senescence (Figure 1; Thomsen et al., 2014). Indeed, this last role has been reinforced recently by the characterization of a triple $g \ln 1-1 / g \ln 1-2 / g \ln 1-3$ mutant of Arabidopsis. This multiple T-DNA insertion line had a lower seed yield and $\mathrm{N}$ remobilization activity from cauline and rosette leaves to seeds under both high and low N conditions (Moison et al., 2018).

In terms of biotechnological applications, a major strategy was to constitutively overexpress specific GS1 cDNAs under the control of a CaMV35S promoter to improve NUpE and NAE in crops under low $\mathrm{N}$ conditions (Table 1). From a global point of view, some interesting results were obtained for Lotus japonicus, Nicotiana tabacum, and Zea mays in terms of NUE. However, significant differences were found depending on the GS1 genes used. Indeed, overexpression of GS1-5 from Glycine max in Nicotiana tabacum decreased plant growth and pod number per plant while only the overexpression of GS1 genes from Pisum sativum succeeded to increase plant biomass under high, moderate, and low N conditions. Since GS1 activity seemed to be rate-limiting for NAE in Nicotiana tabacum, a possible explanation for these differences was that the efficient regulation of the assembly/disassembly of GS1 subunits by phosphorylation, nitration and the redox state of the cells may depend on specific exogenous GS1 isoforms (Thomsen et al., 2014). That said, toxicity of a strong GS1 activity in multiple organs has been observed for Pisum sativum and Oryza sativa. Indeed, GS1 activity has a high energetic cost and can stimulate the import of ammonium from roots thereby contributing to its toxic accumulation. Nevertheless, the simultaneous overexpression of OsGS1.1 and OsGS2 in Oryza sativa increased NAE and plant biomass (Table 1). This surprising result suggested that the GS2 could be a better candidate than GS1 isoforms for NUE improvement. To address the negative effects of GS1 overexpression, either organ-specific or moderate promoters have been used. These strategies were successful for Sorghum bicolor and especially Pisum sativum, where the root-specific 


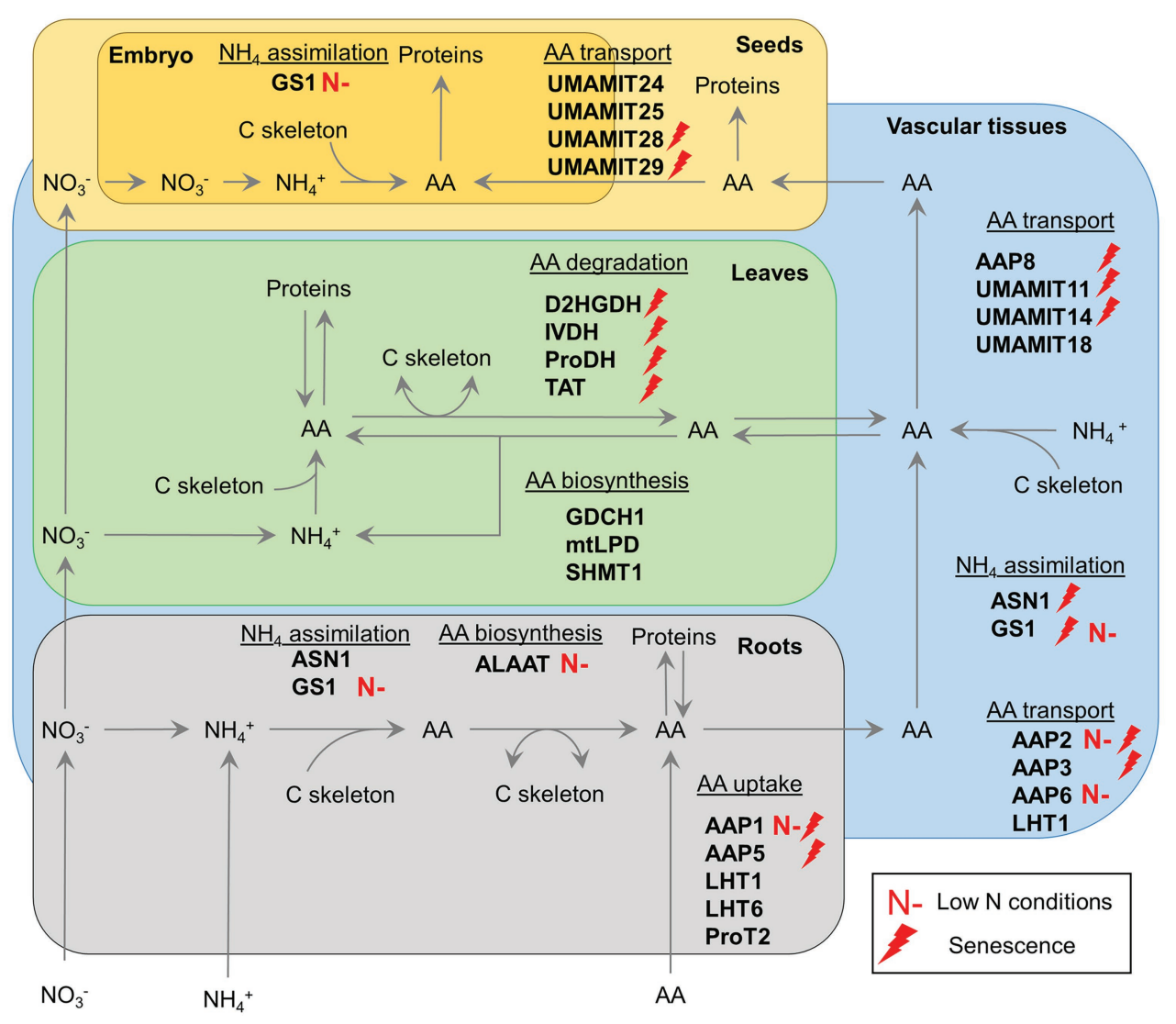

FIGURE 1 | Current and promising targets for genetic manipulation of amino acid metabolism and transport to improve crop nitrogen use efficiency for a sustainable agriculture. Red lightning refers to gene targets known to be upregulated during senescence. Red "N-" refers to targets with a known biotechnological potential in low $\mathrm{N}$ conditions in certain crops. AAP, amino acid permease; ALAAT, alanine:2-oxoglutarate aminotransferase; ASN, asparagine synthetase; D2HGDH, D-2-hydroxyglutarate dehydrogenase; GDCH, $\mathrm{H}$-protein of the glycine decarboxylase complex; GS, glutamine synthetase; IVDH, isovaleryl-CoA dehydrogenase; LHT, lysine histidine transporter; mtLPD, mitochondrial L-protein of the glycine decarboxylase complex; ProDH, proline dehydrogenase; ProT, proline transporter; SHMT, serine hydroxymethyl aminotransferase; TAT, tyrosine aminotransferase; UMAMIT, usually multiple amino acid move in and out transporter.

expression of GS1-5 from Glycine max increased plant biomass and $\mathrm{N}$ uptake in both high and low $\mathrm{N}$ conditions. Recently, the impact of GS1 overexpression has been investigated in Nicotiana tabacum, Oryza sativa, and Hordeum vulgare during abiotic stresses such as drought, salt stress, osmotic stress or elevated $\mathrm{CO}_{2}$ combined with $\mathrm{N}$ limitations. The results indicated that GS1 was a suitable target for improving NUE, grain yield, and tolerance to several different stresses. Taken together, all the results summarized here give interesting perspectives for improving NUE and tolerance to multiple abiotic stresses in many crops by targeting both GS enzymes.

Regarding GOGAT engineering, overexpression of an endogenous NADH-GOGAT (OsGOGAT1) in Oryza sativa increased $\mathrm{NUpE}$ in low $\mathrm{N}$ conditions but grain yield was decreased by up to $50 \%$ (Table 1). Interestingly, pyramiding OsGOGAT1 with a rice gene encoding an ammonium transporter succeeded to rescue this low grain yield phenotype. Unfortunately, this pyramiding strategy was not successful for maize. While the constitutive expression of NADH-GOGAT from wheat decreased shoot dry weight and kernel yield, the introduction of an alternative pathway to boost the biosynthesis of 2-oxoglutarate and glutamine (the two substrates of GOGAT) did not recue the negative phenotype (Canas et al., 2020). Overall, the results were somewhat deceiving, and they appear to suggest that GOGAT activity has a low control coefficient on $\mathrm{N}$ assimilation.

\section{Asparagine Synthetase}

Asparagine synthetase (ASN) can produce asparagine either by the condensation of ammonia and aspartate or by the transamination of glutamine and aspartate. In Arabidopsis, ASN is encoded by three genes: ASN1, ASN2, and ASN3 (Gaufichon et al., 2016). ASN1 and ASN2 are important for AA metabolism and transport (redistribution/remobilization) at the seed filling stage (Gaufichon et al., 2013, 2017). However, ASN1 is preferentially induced by leaf senescence compared to ASN2 and ASN3 (Figure 1; Have et al., 2017). In Arabidopsis, constitutive overexpression of ASN1 using a CaMV35S promoter enhanced $\mathrm{N}$ allocation to seeds by promoting the phloem source-to-sink remobilization of asparagine and significantly increased the thousand seed weight (Lam et al., 2003; Gaufichon et al., 2017). 
TABLE 1 | Transgenic approaches manipulating amino acid metabolism and transport to improve nitrogen use efficiency in crops.

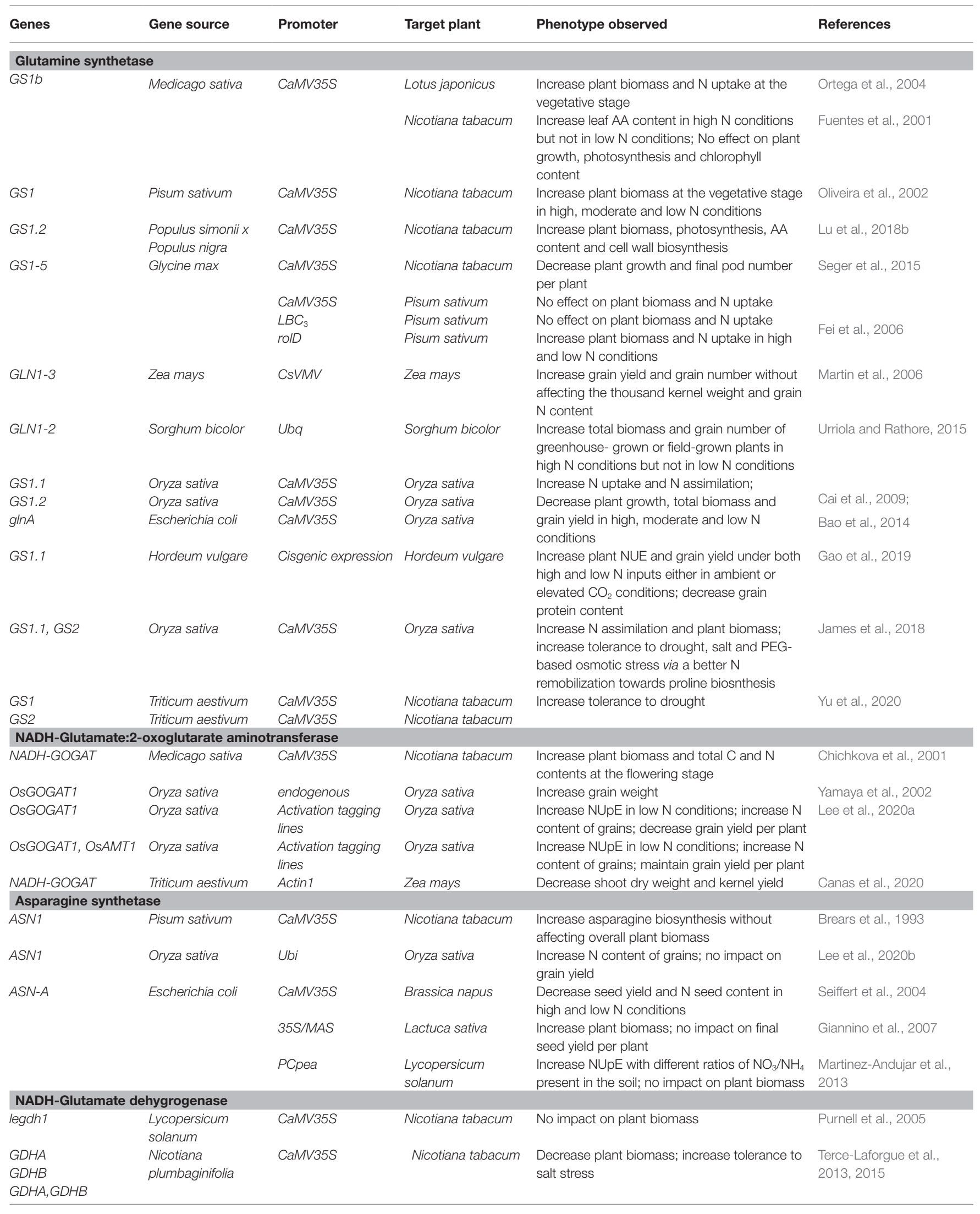


TABLE 1 | Continued

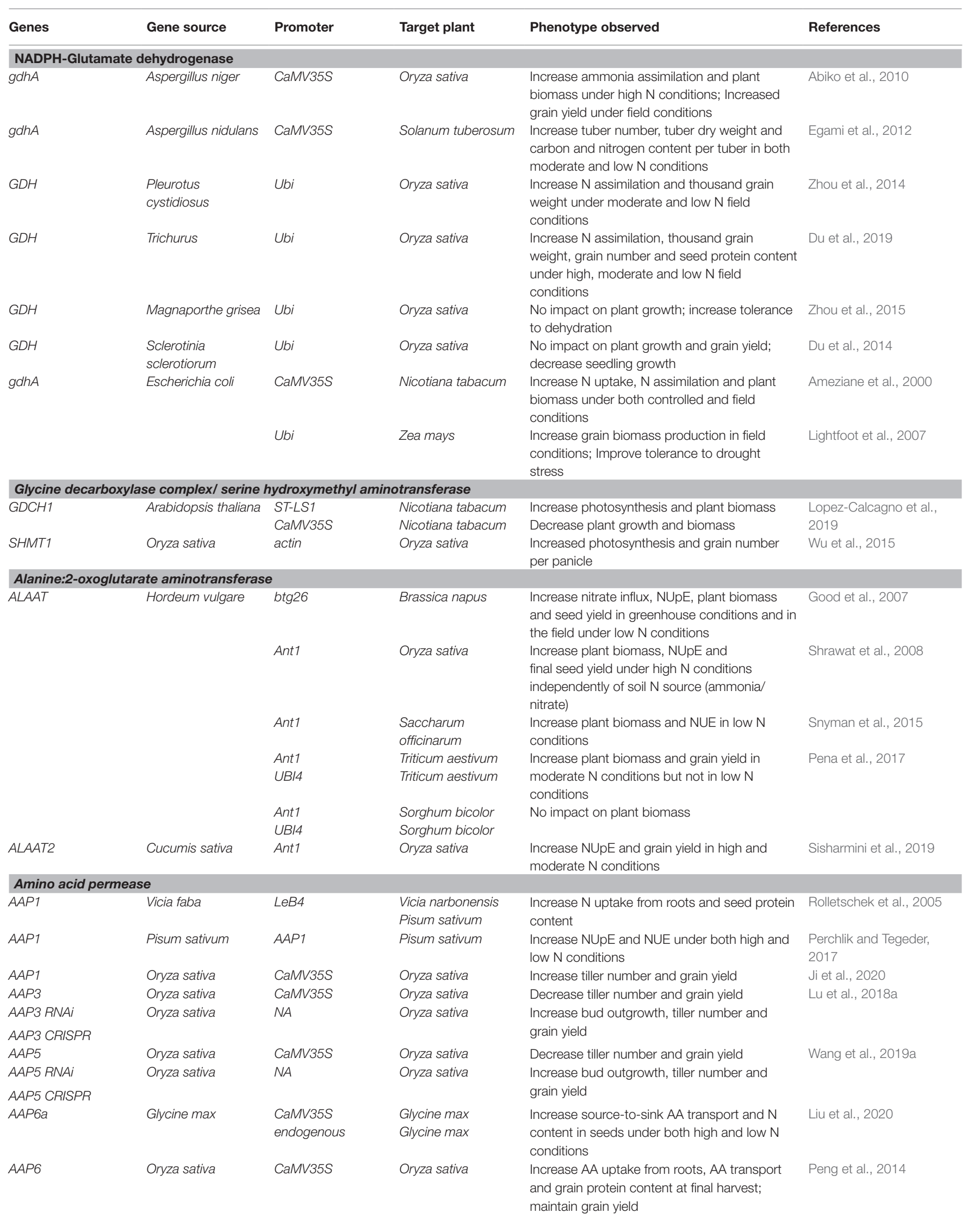


Since plant ASNs play a minor role in primary $\mathrm{N}$ assimilation (compared to GS), an interesting strategy was the overexpression of a bacterial type-A isoform from E. coli (ASN-A), which can only use ammonia as an amide donor compared to plant ASNs. This led to an increase in biomass of Lactuca sativa and NUpE of Lycopersicum solanum but brought about opposite effects in transformed Brassica napus in both high and low $\mathrm{N}$ conditions (Table 1). However, Brassica napus has a highly dynamic apoplastic $\mathrm{NH}_{4}$ pool, which may explain a higher sensibility to an accumulation of ammonia triggered by ASN-A activity (Nielsen and Schjoerring, 1998). A second strategy has consisted of boosting $\mathrm{N}$ reallocation to seeds by overexpressing plant ASNs. Indeed, an increase in total $\mathrm{N}$, protein, and AA content of seeds without affecting grain yield per plant was observed when OsASN1 was overexpressed in Oryza sativa (Lee et al., 2020b). Although plant ASNs have been shown already to represent interesting targets to modulate seed quality without affecting plant biomass, their potential for NUE improvement under low $\mathrm{N}$ conditions must still be addressed.

\section{Glutamate Dehydrogenase}

Glutamate dehydrogenase $(\mathrm{GDH})$ is involved in ammonia assimilation and production by catalyzing the reversible amination of 2-oxoglutarate to glutamate. Plant GDH is located in the cytosol and mitochondria as a multiprotein complex comprising three $\mathrm{NAD}(\mathrm{H})$-dependent subunits $(\alpha, \beta$, and $\gamma$ ) encoded by three genes in Arabidopsis (GDH1, GDH2, and GDH3). A fourth gene GDH4 encoding a putative NADP(H)dependent GDH has been identified in Arabidopsis but its exact catalytic activity and function are both still not clear (Igarashi et al., 2009). Although NADH-GDH can incorporate ammonia into 2-oxoglutarate to form glutamate in response to high levels of ammonia under stress conditions (Skopelitis et al., 2006), the major catalytic activity of NADH-GDH in plant cells is restricted to glutamate deamination and thus ammonia production (Masclaux-Daubresse et al., 2006). However, NADH-GDHmediated glutamate deamination in roots significantly contributes to AA catabolism and TCA cycle activity during dark-induced senescence and hypoxia recovery (Miyashita and Good, 2008; Fontaine et al., 2012; Diab and Limami, 2016). Without surprise, biotechnological engineering of higher plants by overexpressing plant GDH isoforms did not increase either plant biomass or NUpE (Table 1). In tobacco, a better tolerance to salt stress was observed, but plant biomass remained lower when compared to control lines in normal conditions. Consequently, some research groups focused their work on the overexpression of either bacterial or fungal NADPH-GDH (Table 1). Indeed, Aspergillus niger NADPH-GDH $\alpha$-subunit $(g d h A)$ exhibited a higher maximal velocity and affinity for ammonia when compared to plant NADH-GDH and even cytosolic GS1 (Abiko et al., 2010). Except for GDH from two fungi (Sclerotinia sclerotiorum and Magnaporthe grisea), this strategy gave strikingly results in Solanum tuberosum, Oryza sativa, Nicotiana tabacum, and Zea mays. All overexpression lines showed higher $\mathrm{N}$ assimilation when compared to control lines coupled to positive effects on either plant biomass and/ or grain yield under field and/or low $\mathrm{N}$ conditions. Interestingly, fungal and bacterial GDH have a higher potential for the improvement of NUE in crops compared to plant GS1. Indeed, $\mathrm{NAD}(\mathrm{P}) \mathrm{H}-\mathrm{GDH}$ activity produces glutamate, a major AA, which is transported and used in many transamination reactions, by using 2-oxoglutarate, an organic acid efficiently produced by the tricarboxylic acid (TCA) cycle, as a carbon skeleton to fix ammonia. Conversely, GS activity produces glutamine, a transported AA requiring GOGAT enzyme activity to be further converted to glutamate. Therefore, GOGAT activity may become limiting in GS1-overexpressing lines while in GDH-overexpressing lines $\mathrm{N}$ assimilation becomes directly connected to TCA cycle activity and mitochondrial respiration. Considering Oryza sativa, these interesting results with GDH-overexpressing lines may also question a potential toxic accumulation of ammonia in some plant GS1-overexpressing lines, since a strong bacterial/ fungal GDH activity could also stimulate ammonia import. An issue that still needs to be addressed is the phenotypical differences observed when overexpressing different fungal GDHs in Oryza sativa. Indeed, these phenotypical differences cannot be explained by different kinetic parameters since recombinant GDH from Aspergillus niger, Trichuris, and Sclerotinia sclerotiorum exhibited similar Km values for $\mathrm{NH}_{4}$ and 2-oxoglutarate (Abiko et al., 2010; Du et al., 2014, 2019).

\section{AMINO ACID BIOSYNTHESIS AND DEGRADATION}

\section{Photorespiratory N-Related Enzymes}

Under current atmospheric conditions $\left(415 \mu \mathrm{l} . \mathrm{L}^{-1}\right)$, ribulose-1,5bisphosphate carboxylase/oxygenase (Rubisco) oxygenase activity produces 2-phosphoglycolate, which is an inhibitor of CalvinBenson cycle enzymes (Flugel et al., 2017). The photorespiratory cycle metabolizes this toxic 2-phosphoglycolate to make useful 3-phosphoglycerate, a metabolite hub of $\mathrm{C}$ metabolism (Hodges et al., 2016; Timm and Hagemann, 2020). This important pathway takes place in all photosynthetic cells and contributes to the production and degradation of glycine and serine through the successive action of the following enzymes: glutamate: glyoxylate aminotransferase (GGAT), glycine decarboxylase complex (GDC), serine hydroxymethyl aminotransferase (SHMT), and serine:glyoxylate aminotransferase (SGAT). In Arabidopsis, it has been shown that GGT1, SHMT1, and SGAT1 are the photorespiratory genes (Somerville and Ogren, 1980; Voll et al., 2006; Dellero et al., 2015, 2016). GDC is a multiprotein complex comprising four subunits which are also involved in other enzymatic complexes: the P-protein encoded by a single gene (GDP1), the L-protein encoded by two genes (LPD1 and LPD2), the T-protein encoded by a single gene (GDT1), and the H-protein encoded by three genes (GDCH1, GDCH2, and GDCH3; Douce et al., 2001; Engel et al., 2007). Considering that the GDC step releases $\mathrm{CO}_{2}$ and ammonia and that photorespiration cannot be completely suppressed, researchers have improved plant productivity by introducing alternative pathways to optimize the refixation of photorespiratory $\mathrm{CO}_{2}$ and to minimize ammonia losses (Maurino, 2019).

The recent overexpression of specific subunits of the photorespiratory GDC complex intriguingly gave promising 
results that suggested GDC to be the rate-limiting step of the cycle (Timm and Hagemann, 2020; Figure 1, Table 1). Indeed, Arabidopsis lines overexpressing $L P D$ or GDCH genes exhibited an increase in net $\mathrm{CO}_{2}$ assimilation rate and overall plant biomass by up to $20 \%$ at the vegetative stage compared to control lines (Timm et al., 2012, 2015). In tobacco, similar improvements were achieved in field conditions but only when GDCH1 overexpression was driven by a leaf-specific and light-regulated promoter (Lopez-Calcagno et al., 2019). Perhaps surprisingly, the constitutive overexpression of OsSHMT1 in rice significantly increased photosynthetic efficiency and grain number per panicle by up to $25 \%$ (Wu et al., 2015), whereas the overexpression of either SGAT1 or GGAT1 in Arabidopsis did not increase plant biomass (Igarashi et al., 2006; Modde et al., 2017).

Given these results, it is tempting to think that the phenotype of plants overexpressing subunits of the GDC complex or SHMT1 may be due to a modified flux through the photorespiratory cycle thus reducing the accumulation of toxic photorespiratory intermediates rather than an altered glycine/serine metabolism. Indeed, lower amounts of 2-phosphoglycolate would improve Calvin-Benson cycle activity, RuBisCO net $\mathrm{CO}_{2}$ fixation, and ultimately plant growth and $\mathrm{N}$ management. That said, the overexpression of PGLP1 in Arabidopsis did not significantly increase plant biomass and photosynthetic performances under current atmospheric conditions $\left(21 \% \mathrm{O}_{2}\right.$; Flugel et al., 2017). However, these transgenic lines showed a higher photosynthetic rate when compared to control lines without changing their water use efficiency under drought stress (Timm et al., 2019). As yet, we do not know whether overexpressing GDC subunits or SHMT1 confers an advantage under drought stress or low $\mathrm{N}$ inputs. This perspective may be promising for improving plant NUE with respect to climate change conditions.

\section{Alanine:2-Oxoglutarate Aminotransferase}

Plant alanine:2-oxoglutarate aminotransferase (ALAAT) catalyzes the reversible transamination of glutamate and pyruvate to produce 2-oxoglutarate and alanine in the cytosol and mitochondria of various cell types. In Arabidopsis, mitochondrial ALAAT is encoded by two genes: ALAAT1, which is strongly expressed in vascular tissues of shoots and roots compared to ALAAT2, which is weakly expressed in vascular tissues of shoots (Ricoult et al., 2006; Miyashita et al., 2007). Interestingly, ALAAT1 is induced in roots when plants are facing hypoxia stress such as waterlogging, where it plays an essential role in storing $\mathrm{C}$ and $\mathrm{N}$ skeletons and optimizing ATP production (Diab and Limami, 2016).

A successful strategy for crop improvement consisted in the root specific expression of a barley HVALAAT1 cDNA (Table 1). This led to an increase in NUpE, plant biomass, and seed yield in Brassica napus, Oryza sativa, Sacharum officinarum, and Triticum aestivum, although these results were sometimes only observed in high $\mathrm{N}$ conditions or low $\mathrm{N}$ conditions depending on the crop tested. In addition, neither root-specific nor constitutive expression of HvALAAT1 using an ubiquitin promoter succeeded to increase plant biomass in Sorghum bicolor, and thus suggesting that ALAAT activity was not rate-limiting for NUE in Sorghum bicolor. Recent results have confirmed a link between a higher ALAAT activity in roots and improved N-related phenotypes since the expression of ALAAT2 from Cucumis sativus, ALAAT1 and ALAAT2 from Mus musculus, and ALAAT from Pyrococcus furiosus in either Arabidopsis or Oryza sativa successfully increased plant growth in high or low $\mathrm{N}$ conditions (McAllister and Good, 2015; Sisharmini et al., 2019). How ALAAT activity leads to improved agronomical performance of plants has not been clearly elucidated (McAllister et al., 2012). However, based on some of the phenotypes observed in overexpressing lines, ALAAT could contribute to plant fitness in several ways. First, ALAAT may stimulate glycolysis and thereafter TCA cycle activity in roots by actively consuming pyruvate. Second, ALAAT may boost $\mathrm{N}$ uptake and assimilation in roots by actively recycling glutamate to 2-oxoglutarate for GOGAT activity. Finally, overproduction of alanine through ALAAT activity may efficiently activate alanine transport between plant organs thereby increasing the sink demand for $\mathrm{N}$.

\section{Amino Acid Catabolism During Leaf Senescence}

The regulation of the balance of AA and protein biosynthesis and degradation in plant cells is of primary importance to support different plant growth stages (Hildebrandt et al., 2015). Specifically, when cells are facing senescence or adverse stresses, the activation of autophagy processes results in an intense degradation of stored proteins (Masclaux-Daubresse et al., 2017). This mechanism allows plants to remobilize $\mathrm{C}$ and $\mathrm{N}$ for the production of valuable compounds for stress tolerance/adaptation, for the production of energy, and for the establishment of sink tissues (Hildebrandt, 2018; Tegeder and Masclaux-Daubresse, 2018). Interestingly, developmental and dark-induced senescence (prolonged dark stress) share common pathways for the regulation of AA metabolism and this includes the activation of the mitochondrial catabolism of branched-chain amino acids (BCAAs; namely leucine, valine, and isoleucine; Chrobok et al., 2016; Law et al., 2018; Figure 1). This metabolic pathway is of primary importance since it recycles the $\mathrm{N}$ of each BCAA while redirecting their $\mathrm{C}$ skeleton to the TCA cycle in the form of acetyl-CoA. At the same time, this AA catabolism actively participates in mitochondrial energy production, by providing electrons to a flavoprotein of the ubiquinone complex of the mitochondrial electron transfer chain (METC; Figure 2; Araujo et al., 2010; Hildebrandt et al., 2015). Since ammonia reassimilation during senescence and $\mathrm{AA}$ transport both require ATP to function, BCAA catabolism represents a promising target to boost source-to-sink $\mathrm{N}$ remobilization in plants by remobilizing $\mathrm{N}$ from BCAAs while participating in mitochondrial ATP production.

Besides BCAAs, the catabolism of other AAs can also contribute to mitochondrial energy production during darkinduced senescence (Figure 2). The characterization of a D-2-hydroxyglutarate dehydrogenase (D2HGDH) Arabidopsis mutant $d 2 h g d h$ coupled to ${ }^{13} \mathrm{C}$-lysine labeling experiments confirmed that lysine degradation via D2HGDH supplied electrons to the METC during dark-induced senescence (Araujo et al., 2010). Recently, the analysis of Arabidopsis tyrosine aminotransferase 1 mutants showed that Tyr degradation 
significantly contributed to TCA cycle activity during dark-induced senescence by supplying fumarate (Wang et al., 2019b). Proline dehydrogenase (ProDH), the first enzyme of mitochondrial degradation of proline, has also attracted attention. In Arabidopsis, ProDH1 can form part of a low-molecular-mass complex in the mitochondrial membrane and actively contribute to the METC by acting as an electron donor (Cabassa-Hourton et al., 2016). The analysis of a prodh1prodh2 double mutant confirmed that the proline oxidation significantly contributed to the METC during dark-induced senescence (Launay et al., 2019). In oilseed rape, certain BnProDH homologous genes (BnaA\&CProDH1a, BnaA\&CProDH1b, BnaAProDH2a, and BnaCProDH2a) were induced by prolonged dark conditions (Dellero et al., 2020a). However, variations of proline content between sink and source-to-senescent leaves at the vegetative stage were mostly correlated to a reduction of proline biosynthesis rather than to an increase of proline oxidation (Dellero et al., 2020a,b). This recent finding has questioned the importance of proline catabolism with respect to crop improvement. In potato, the short-term inhibition of the activity of the 2-oxoglutarate dehydrogenase complex (involved in the production of succinate in the TCA cycle) with a phosphonate analog resulted in a severe inhibition of mitochondrial respiration (Araujo et al., 2008). Nevertheless, long-term downregulation of this complex by antisense inhibition in tomato slightly reduced plant biomass and flowering time without affecting final fruit size, thereby suggesting that METC activity required for fruit production can be supported by alternative substrates (Araujo et al., 2012). Since isoleucine, leucine, lysine, proline, valine, and tyrosine are used as alternative respiratory substrates for mitochondrial respiration in plants during dark-induced senescence, enzymes of their respective catabolic pathways represent interesting and promising targets to boost sourceto-sink $\mathrm{N}$ remobilization in plants. Extending this work to other crops will definitely provide exciting results on the exact contribution of their catabolism on plant NUE and perhaps under low $\mathrm{N}$ conditions.

\section{AMINO ACID UPTAKE AND TRANSPORT}

During vegetative growth and reproductive stages, AAs are transported from soil to roots (AA uptake) and between roots, shoots, and sink tissues through the vascular tissues of xylem and phloem. AA transport from roots to shoots is apoplasmically achieved by the xylem and xylem loading is expected to be a passive step since it is facilitated by the difference of water potential between roots and leaves (Rennie and Turgeon, 2009). AA transport from source leaves to sink tissues is symplasmically achieved through the phloem. However, phloem loading and unloading events and xylem-to-phloem loading can also follow an apoplasmic route, which require the activity of specific plasma membrane AA transporters (Tegeder and MasclauxDaubresse, 2018). These transporters are involved in the cellular import of a broad range of AAs in co-transport with protons, and they belong to five multigene families: amino acid permeases (AAP; eight genes in Arabidopsis), cationic amino acid transporters (CAT; nine genes in Arabidopsis), lysine histidine transporters (LHT; ten genes in Arabidopsis), proline transporters (ProT; three genes in Arabidopsis), and "usually multiple amino acid move in and out transporters" (UMAMIT; 43 genes in Arabidopsis; Su et al., 2004; Lehmann et al., 2011; Tegeder and Ward, 2012; Dinkeloo et al., 2018).

Reverse genetic approaches based on the characterization of Arabidopsis mutants have succeeded to identify the function of many AA transporters in recent years (Figure 1). Concerning AA uptake, the disruption of AAP1, AAP5, LHT1, LHT6, or ProT2 expression successfully decreased AA uptake capacities in the corresponding transgenic plants (Lee et al., 2007; Svennerstam et al., 2007, 2011; Lehmann et al., 2011; Perchlik et al., 2014). In addition, AAP1 can contribute to salt stressinduced proline uptake while LHT1 plays a role in AA import into leaf cells (Hirner et al., 2006; Wang et al., 2017). However, the importance of AAP1 for crop improvement can be questioned since potato StAAP1 antisense lines showed no differences with respect to $\mathrm{C}$ and $\mathrm{N}$ contents in seeds and overall seed yield when compared to control lines (Koch et al., 2003). Concerning AA export from either roots or source leaves, AAP2 and AAP6 play a key role in xylem-to-phloem loading of AAs while the role of AAP3 seems to be easily compensated by other AA transporters (Figure 1; Okumoto et al., 2004; Hunt et al., 2010; Zhang et al., 2010). AAP8 and UMAMIT18 are involved in phloem loading of AA for leaf export (Figure 1; Ladwig et al., 2012; Santiago and Tegeder, 2016, 2017). Interestingly, deletion of Arabidopsis AAP8 decreased AA exudation from leaves at both vegetative and reproductive stages and ultimately decreased seed yield by up to $40 \%$ compared to the control line. Concerning AA import into seeds, UMAMIT11 and UMAMIT14 are both responsible for phloem unloading of AAs to seeds while UMAMIT24, UMAMIT25, UMAMIT28, and UMAMIT29 are involved in seed loading of AAs (Figure 1; Muller et al., 2015; Besnard et al., 2016, 2018). Perhaps surprisingly, single deletion of UMAMIT11, UMAMIT14, UMAMIT28, or UMAMIT29 decreased seed size at final harvest. From a global point of view, many AAP and UMAMIT transporters mentioned here are transcriptionally upregulated during natural leaf senescence and represent interesting targets for crop improvement (Figure 1; Have et al., 2017).

Up until now, biotechnological engineering of AA transport has been essentially focused on AAPs (Table 1). A successful strategy has consisted in the overexpression of AAP1 and AAP6 in different tissues (phloem, embryo, seed, or all plant organs) to improve AA transport from source-to-sink tissues in Vicia narbonensis, Pisum sativum, Oryza sativa, and Glycine max. Consequently, these overexpressing plants exhibited higher $\mathrm{N}$ root uptake and/or AA transport capacities in both high and low $\mathrm{N}$ conditions, thereby resulting in higher $\mathrm{N}$ seed content and/or seed yield. From a global view, similar phenotypes were observed by using promoters differing in strength and conferring different tissue localizations. This confirmed the multifunctional role of AAP1 and AAP6 in plant N metabolism and highlighted them as valuable targets for crop improvement. However, this overexpression strategy was not successful for other AAPs, hence reinforcing the interest of exploring the roles of AAPs 
specifically in crops. Indeed, the constitutive overexpression of OsAAP5 and OSAAP3 in rice gave negative NUE phenotypes while either RNA interference or genome-editing of these genes using CRISPR technologies (Clustered Regularly Interspaced Short Palindromic Repeats) increased bud outgrowth and tiller number by up to $30 \%$ and grain yield by up to $50 \%$. Perhaps such results reflect the fact that OsAAP3 and OsAAP5 can promote the uptake of lysine and arginine from roots and these AAs can inhibit specifically root growth and axillary bud outgrowth in rice through the negative regulation of cytokinin production. Similarly, Arabidopsis knock-out lines for AAP2 showed a better NUpE and seed yield under both high and low $\mathrm{N}$ conditions. Nevertheless, interesting phenotypes obtained by downregulating AA transport seems to be restricted to AAP only. In fact, the downregulation of OsLHT1 in rice through either knock-out or CRISPR technology inhibited AA uptake from roots and their translocation to leaves while negatively impacting plant growth, and finally, seed yield by up to 50\% (Wang et al., 2019c; Guo et al., 2020).

It can be seen above that the potential of AAP and UMAMIT genes for improving NUE in N-limiting conditions has not been fully investigated among crops while the recent genomewide identification of $A A P$ genes and their regulation during various stresses in many crops will definitely provide interesting targets for the future improvement of crop NUE (Ma et al., 2016; Wan et al., 2017; Qu et al., 2019; Duan et al., 2020; Zhou et al., 2020).

\section{CONCLUDING REMARKS AND PERSPECTIVES}

Over the two last decades, major advances have been achieved to improve NAE and NUE under high and low N conditions through the genetic manipulation of AA metabolism. Concerning NAE improvement, while plant GS1 has represented an interesting target, breakthrough results in low $\mathrm{N}$ conditions for many crops have been obtained mainly by expressing in bacterial ASN and fungal and bacterial GDH genes in plants. Indeed, plant GS1 activity is regulated at multiple levels and represents a rather high energetic cost; therefore, an uncontrolled increase of GS1 activity is prone to interfere with plant physiology and metabolic cell homeostasis. Probably bacterial ASN and fungal and bacterial GDH are insensitive to plant cell regulations and their in vitro affinity for ammonia appears to be much better when compared to GS1. Thus, an interesting strategy to maintain NAE while reducing field $\mathrm{N}$ inputs could consist in the overexpression of non-plant ASN and GDH isoforms. However, we do not know whether any beneficial effects in low $\mathrm{N}$ conditions would be conserved in the context of climate change, i.e., in combination with elevated $\mathrm{CO}_{2}$ and temperatures as well as prolonged periods of drought. Work performed using Nicotiana tabacum, Hordeum vulgare, and Oryza sativa clearly illustrated that plant GS1 remains an interesting target for this purpose (Table 1). Since a gene-pyramiding strategy for OsGS1.1 and OsGS2 in Oryza sativa gave attractive results, it might be interesting to boost ATP production while overexpressing plant GS1. For this purpose, targeting branched-chain AA catabolism may be a promising strategy. One may question the interest of boosting both AA biosynthesis and AA degradation. However, AA catabolism is often activated during stress-induced senescence and it has a high capacity for ATP production compared to the ATP required to reassimilate their $\mathrm{N}$. The complete oxidation of a molecule of either BCAA, Lys, Pro, and Tyr releases around 29 ATP while the reassimilation of their $\mathrm{N}$ requires only 1 ATP (Hildebrandt et al., 2015). Therefore, this strategy could be ideal during senescence-inducing stress conditions by optimizing the redirection of carbon and nitrogen fluxes within plant cells. Specifically, the potential of IVDH, an enzyme that can participate in both lysine and valine catabolism, should be further evaluated within a gene pyramiding context.

Besides $\mathrm{N}$ assimilation and AA remobilization, AA transport represents an important rate-limiting step for NUE in many crops. This transport is of prime importance for NUE, as it affects $\mathrm{N}$ uptake, sink/source relationships, and ultimately seed $\mathrm{N}$ content. The assessment of the biotechnological potential of many AAPs in Arabidopsis has contributed to the development of genetic engineering approaches targeting AAPs in crops. However, results obtained with Oryza sativa confirmed that a strong AA transport activity can sometimes interfere with plant physiology (via cytokinin balance), and that this behavior is largely dependent on $\mathrm{N}$ metabolism topology in the tested crop. Of course, boosting AA uptake by overexpressing AAP1 and AAP6 in different tissues always resulted in a higher final seed $\mathrm{N}$ content in many different crops and even in low $\mathrm{N}$ conditions for the two leguminous species Pisum sativum and Glycine max. However, there was not always a positive impact on plant biomass or grain yield, perhaps due to limitations in sink size. In fact, successful engineering of sink/source relationships was mainly achieved through multi-target transformations improving both $\mathrm{C} / \mathrm{N}$ remobilization and sink strength/size (Sonnewald and Fernie, 2018). It was recently shown that $\mathrm{N}$ reassimilation via the photorespiratory pathway increased plant net $\mathrm{CO}_{2}$ uptake (Busch et al., 2018). Therefore, overexpression of either AAP1/AAP6 in crops could be coupled with the overexpression of photorespiratory proteins at the interface between $\mathrm{C}$ and $\mathrm{N}$ metabolisms, such as GDCH and SHMT1.

The identification of new targets for genetic engineering represents a major challenge. Given that a systematic knock-out/ overexpression approach for each potential target in different crops would represent a tedious and time-consuming strategy, the development of ${ }^{15} \mathrm{~N}$-based fluxomic approaches using crops could help to identify novel, suitable metabolic steps to target for NUE improvement. Whole-plant ${ }^{15} \mathrm{~N}$-based fluxomic approaches have been deployed already to analyze the impact of low $\mathrm{N}$ conditions on global NUpE and NUtE at the organ level and to identify the origin of $\mathrm{N}$ allocated to seeds (Have et al., 2017; Salon et al., 2017). Therefore, the further development of ${ }^{15} \mathrm{~N}$-based fluxomics to explore AA metabolism in crops would be highly beneficial. For instance, the recent use of scalable metabolic flux modeling after ${ }^{15} \mathrm{~N}$-glycine labeling showed that metabolic fluxes associated with de novo biosynthesis of proline and valine were strongly affected by leaf sink/source balances in Brassica napus (Dellero et al., 2020b). Future work 


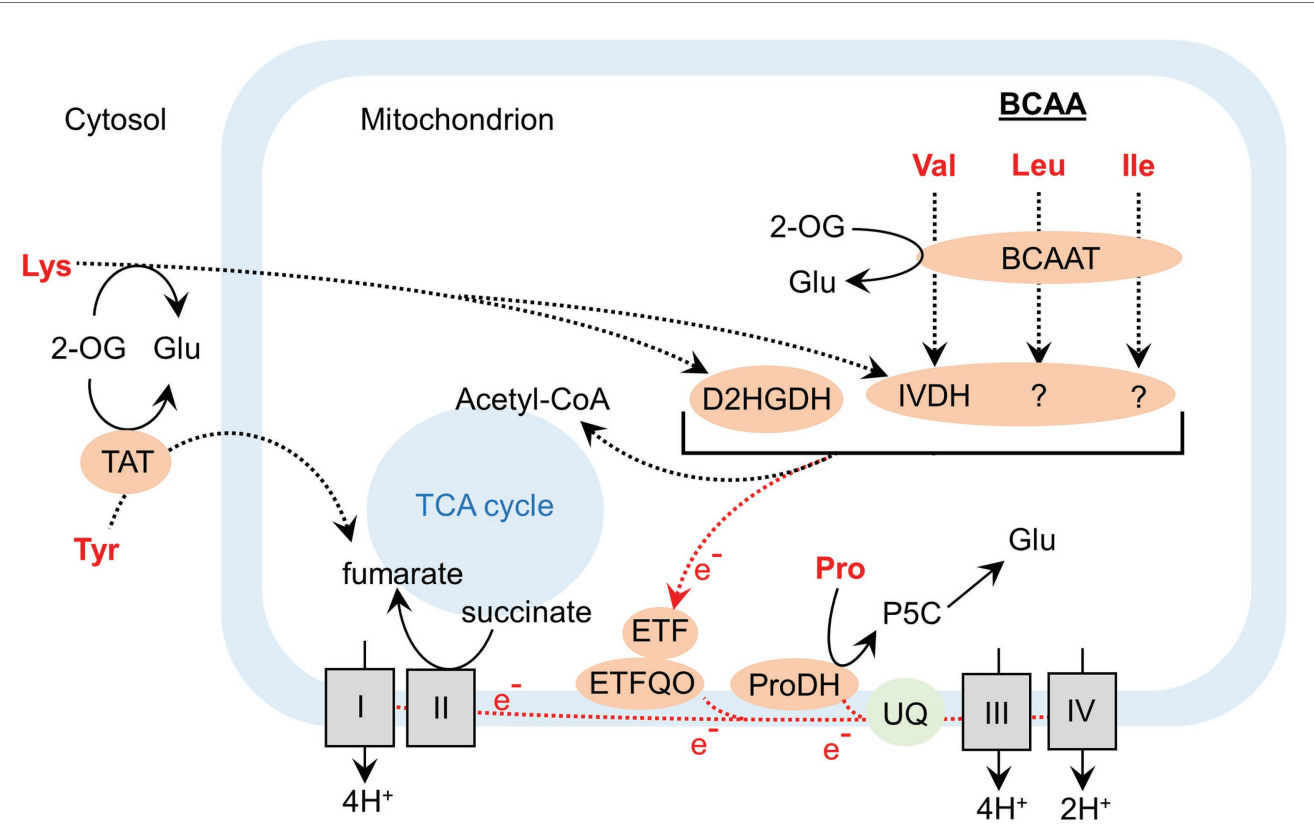

FIGURE 2 | Contribution of amino acid catabolism to the activity of the tricarboxylic acid cycle and to the mitochondrial electron transfer chain during dark-induced senescence in Arabidopsis. BCAAT, branched-chain amino acid aminotransferase; D2HGDH, D-2-hydroxyglutarate dehydrogenase; ETF, electron-transfer flavoprotein; ETFQO, electron-transfer flavoprotein:ubiquinone oxidoreductase; IVDH, isovaleryl-CoA dehydrogenase ProDH, proline dehydrogenase; P5C, 1-pyrroline-5-carboxylic acid; TAT, tyrosine aminotransferase; TCA, tricarboxylic acid; UQ, ubiquinone; 2-OG, 2-oxoglutarate.

should focus on developing more detailed and complete isotopic models of compartmented AA metabolism in crops under normal and low $\mathrm{N}$ conditions to identify new targets to improve NUE (and abiotic stress tolerance).

An important future challenge to consider regarding the improvement of crop NUE for sustainable agriculture is to propose non-GMO (Genetically Modified Organism) strategies. Indeed, genetically modified plants are not always publicly accepted especially in Europe due to a strong lobbying by environmental organizations. Forward genetic approaches based on natural genetic variation in crops have led to some interesting results for GS and AAPs. A QTL analysis of Oryza sativa identified OSAAP6 as a positive regulator of grain protein content and AA uptake. Interestingly, the genetic diversity of grain protein content within indica cultivars was associated to two variations in the potential cis-regulatory elements of the OsAAP6 5'-untranslated region (Peng et al., 2014). Similarly, a genetic analysis in Oryza sativa identified an indica haplotype containing a $51 \mathrm{bp}$ insertion in the promoter sequence of AAP5 compared to japonica haplotypes. The indica haplotype had a lower OsAAP5 transcript level and produced more tillers than japonica haplotypes (Wang et al., 2019a). Different genetic analysis in Triticum aestivum and Zea mays successfully identified GS-containing QTLs related to NUE parameters (N uptake and biomass; Fontaine et al., 2009; Li et al., 2015; Silva et al., 2018). In addition to these interesting perspectives, it is well-known that monocultural farming practices can impoverish the genetic diversity of soil microbiota, which is an important and overlooked actor of plant $\mathrm{N}$ metabolism by directly connecting plants to their neighboring environment.
A major beneficial effect of bacteria on plant $\mathrm{N}$ acquisition is the symbiotic relationship between rhizobia and leguminous plants (Dellagi et al., 2020). While this bacteria-plant symbiotic interaction essentially occurs within Fabaceae, some plantgrowth-promoting rhizobacteria and arbuscular mycorrhizal fungi with a wide-range of specificity for crops may have an interesting potential for the improvement of plant $\mathrm{N}$ nutrition that should be further evaluated.

\section{AUTHOR CONTRIBUTIONS}

The author confirms being the sole contributor of this work and has approved it for publication.

\section{FUNDING}

This work was supported by the FLUCOLSA project funded by a "Young Researcher" grant from the "Institut National pour la Recherche, l'agronomie et l'environnement" (INRAE) and the RAPSODYN project (ANR-11-BTBR-0004) funded by the program "Investments for the Future."

\section{ACKNOWLEDGMENTS}

YD would like to thank Michael Hodges (IPS2, CNRS, Université Paris-Saclay, France) for interesting scientific comments, manuscript editing, and English proofreading. 


\section{REFERENCES}

Abiko, T., Wakayama, M., Kawakami, A., Obara, M., Kisaka, H., Miwa, T., et al. (2010). Changes in nitrogen assimilation, metabolism, and growth in transgenic rice plants expressing a fungal $\mathrm{NADP}(\mathrm{H})$-dependent glutamate dehydrogenase (gdhA). Planta 232, 299-311. doi: 10.1007/s00425-010-1172-3

Ameziane, R., Bernhard, K., and Lightfoot, D. (2000). Expression of the bacterial gdhA gene encoding NADPH glutamate dehydrogenase in tobacco affects plant growth and development. Plant Soil 221, 47-57. doi: 10.1023/A:1004794000267

Araujo, W. L., Ishizaki, K., Nunes-Nesi, A., Larson, T. R., Tohge, T., Krahnert, I., et al. (2010). Identification of the 2-hydroxyglutarate and isovaleryl-CoA dehydrogenases as alternative electron donors linking lysine catabolism to the electron transport chain of Arabidopsis mitochondria. Plant Cell 22, 1549-1563. doi: 10.1105/tpc.110.075630

Araujo, W. L., Nunes-Nesi, A., Nikoloski, Z., Sweetlove, L. J., and Fernie, A. R. (2012). Metabolic control and regulation of the tricarboxylic acid cycle in photosynthetic and heterotrophic plant tissues. Plant Cell Environ. 35, 1-21. doi: $10.1111 / \mathrm{j} .1365-3040.2011 .02332 . x$

Araujo, W. L., Nunes-Nesi, A., Trenkamp, S., Bunik, V. I., and Fernie, A. R. (2008). Inhibition of 2-oxoglutarate dehydrogenase in potato tuber suggests the enzyme is limiting for respiration and confirms its importance in nitrogen assimilation. Plant Physiol. 148, 1782-1796. doi: 10.1104/pp.108.126219

Avice, J. C., and Etienne, P. (2014). Leaf senescence and nitrogen remobilization efficiency in oilseed rape (Brassica napus L.). J. Exp. Bot. 65, 3813-3824. doi: $10.1093 /$ jxb/eru177

Avila-Ospina, L., Marmagne, A., Talbotec, J., Krupinska, K., and Masclaux-Daubresse, C. (2015). The identification of new cytosolic glutamine synthetase and asparagine synthetase genes in barley (Hordeum vulgare L.), and their expression during leaf senescence. J. Exp. Bot. 66, 2013-2026. doi: $10.1093 /$ jxb/erv003

Bao, A., Zhao, Z., Ding, G., Shi, L., Xu, F., and Cai, H. (2014). Accumulated expression level of cytosolic glutamine synthetase 1 gene (OsGS1;1 or OsGS1;2) alter plant development and the carbon-nitrogen metabolic status in rice. PLoS One 9:e95581. doi: 10.1371/journal.pone.0095581

Behera, S. N., Sharma, M., Aneja, V. P., and Balasubramanian, R. (2013). Ammonia in the atmosphere: a review on emission sources, atmospheric chemistry and deposition on terrestrial bodies. Environ. Sci. Pollut. Res. Int. 20, 8092-8131. doi: 10.1007/s11356-013-2051-9

Besnard, J., Pratelli, R., Zhao, C., Sonawala, U., Collakova, E., Pilot, G., et al. (2016). UMAMIT14 is an amino acid exporter involved in phloem unloading in Arabidopsis roots. J. Exp. Bot. 67, 6385-6397. doi: 10.1093/jxb/erw412

Besnard, J., Zhao, C., Avice, J. C., Vitha, S., Hyodo, A., Pilot, G., et al. (2018). Arabidopsis UMAMIT24 and 25 are amino acid exporters involved in seed loading. J. Exp. Bot. 69, 5221-5232. doi: 10.1093/jxb/ery302

Bouchet, A. S., Laperche, A., Bissuel-Belaygue, C., Baron, C., Morice, J., Rousseau-Gueutin, M., et al. (2016). Genetic basis of nitrogen use efficiency and yield stability across environments in winter rapeseed. BMC Genet. 17:131. doi: 10.1186/s12863-016-0432-z

Brears, T., Liu, C., Knight, T. J., and Coruzzi, G. M. (1993). Ectopic overexpression of asparagine synthetase in transgenic tobacco. Plant Physiol. 103, 1285-1290. doi: $10.1104 /$ pp.103.4.1285

Busch, F. A., Sage, R. F., and Farquhar, G. D. (2018). Plants increase $\mathrm{CO}_{2}$ uptake by assimilating nitrogen via the photorespiratory pathway. Nat. Plants 4, 46-54. doi: 10.1038/s41477-017-0065-x

Cabassa-Hourton, C., Schertl, P., Bordenave-Jacquemin, M., Saadallah, K., Guivarc'h, A., Lebreton, S., et al. (2016). Proteomic and functional analysis of proline dehydrogenase 1 link proline catabolism to mitochondrial electron transport in Arabidopsis thaliana. Biochem. J. 473, 2623-2634. doi: 10.1042/ BCJ20160314

Cai, H., Zhou, Y., Xiao, J., Li, X., Zhang, Q., and Lian, X. (2009). Overexpressed glutamine synthetase gene modifies nitrogen metabolism and abiotic stress responses in rice. Plant Cell Rep. 28, 527-537. doi: 10.1007/s00299-008-0665-Z

Canas, R. A., Yesbergenova-Cuny, Z., Belanger, L., Rouster, J., Brule, L., Gilard, F., et al. (2020). NADH-GOGAT overexpression does not improve maize (Zea mays L.) performance even when pyramiding with NAD-IDH, GDH and GS. Plants 9:130. doi: 10.3390/plants9020130

Chichkova, S., Arellano, J., Vance, C. P., and Hernández, G. (2001). Transgenic tobacco plants that overexpress alfalfa NADH-glutamate synthase have higher carbon and nitrogen content. J. Exp. Bot. 52, 2079-2087. doi: 10.1093/ jexbot/52.364.2079

Chrobok, D., Law, S. R., Brouwer, B., Linden, P., Ziolkowska, A., Liebsch, D., et al. (2016). Dissecting the metabolic role of mitochondria during developmental leaf senescence. Plant Physiol. 172, 2132-2153. doi: 10.1104/ pp.16.01463

Dellagi, A., Quillere, I., and Hirel, B. (2020). Beneficial soil-borne bacteria and fungi: a promising way to improve plant nitrogen acquisition. J. Exp. Bot. 71, 4469-4479. doi: 10.1093/jxb/eraa112

Dellero, Y., Clouet, V., Marnet, N., Pellizzaro, A., Dechaumet, S., Niogret, M. F., et al. (2020a). Leaf status and environmental signals jointly regulate proline metabolism in winter oilseed rape. J. Exp. Bot. 71, 2098-2111. doi: 10.1093/ jxb/erz538

Dellero, Y., Heuillet, M., Marnet, N., Bellvert, F., Millard, P., and Bouchereau, A. (2020b). Sink/source balance of leaves influences amino acid pools and their associated metabolic fluxes in winter oilseed rape (Brassica napus L.). Meta 10:150. doi: 10.3390/metabo10040150

Dellero, Y., Jossier, M., Schmitz, J., Maurino, V. G., and Hodges, M. (2016). Photorespiratory glycolate-glyoxylate metabolism. J. Exp. Bot. 67, 3041-3052. doi: $10.1093 /$ jxb/erw090

Dellero, Y., Lamothe-Sibold, M., Jossier, M., and Hodges, M. (2015). Arabidopsis thaliana ggt1 photorespiratory mutants maintain leaf carbon/nitrogen balance by reducing RuBisCO content and plant growth. Plant J. 83, 1005-1018. doi: $10.1111 /$ tpj. 12945

Diab, H., and Limami, A. M. (2016). Reconfiguration of N metabolism upon hypoxia stress and recovery: roles of alanine aminotransferase (AlaAT) and glutamate dehydrogenase (GDH). Plants 5:25. doi: 10.3390/plants5020025

Dinkeloo, K., Boyd, S., and Pilot, G. (2018). Update on amino acid transporter functions and on possible amino acid sensing mechanisms in plants. Semin. Cell Dev. Biol. 74, 105-113. doi: 10.1016/j.semcdb.2017.07.010

Douce, R., Bourguignon, J., Neuburger, M., and Rebeille, F. (2001). The glycine decarboxylase system: a fascinating complex. Trends Plant Sci. 6, 167-176. doi: 10.1016/s1360-1385(01)01892-1

Du, C. Q., Lin, J. Z., Dong, L. A., Liu, C., Tang, D. Y., Yan, L., et al. (2019). Overexpression of an $\mathrm{NADP}(\mathrm{H})$-dependent glutamate dehydrogenase gene, TrGDH, from Trichurus improves nitrogen assimilation, growth status and grain weight per plant in rice. Breed. Sci. 69, 429-438. doi: 10.1270/jsbbs.19014

Du, C., Lin, J., Yang, Y., Liu, H., Li, C., Zhou, Y., et al. (2014). Molecular cloning, characterization and function analysis of a GDH gene from Sclerotinia sclerotiorum in rice. Mol. Biol. Rep. 41, 3683-3693. doi: 10.1007/ s11033-014-3233-3

Duan, Y., Zhu, X., Shen, J., Xing, H., Zou, Z., Ma, Y., et al. (2020). Genomewide identification, characterization and expression analysis of the amino acid permease gene family in tea plants (Camellia sinensis). Genomics 112 2866-2874. doi: 10.1016/j.ygeno.2020.03.026

Egami, T., Wakayama, M., Aoki, N., Sasaki, H., Kisaka, H., Miwa, T., et al. (2012). The effects of introduction of a fungal glutamate dehydrogenase gene $(g d h A)$ on the photosynthetic rates, biomass, carbon and nitrogen contents in transgenic potato. Plant Biotechnol. 29, 57-64. doi: 10.5511/ plantbiotechnology.12.0127a

Engel, N., van den Daele, K., Kolukisaoglu, U., Morgenthal, K., Weckwerth, W., Parnik, T., et al. (2007). Deletion of glycine decarboxylase in Arabidopsis is lethal under nonphotorespiratory conditions. Plant Physiol. 144, 1328-1335. doi: 10.1104/pp.107.099317

Fei, H., Chaillou, S., Hirel, B., Polowick, P., Mahon, J. D., and Vessey, J. K. (2006). Effects of the overexpression of a soybean cytosolic glutamine synthetase gene (GS15) linked to organ-specific promoters on growth and nitrogen accumulation of pea plants supplied with ammonium. Plant Physiol. Biochem. 44, 543-550. doi: 10.1016/j.plaphy.2006.09.007

Flugel, F., Timm, S., Arrivault, S., Florian, A., Stitt, M., Fernie, A. R., et al. (2017). The Photorespiratory metabolite 2-Phosphoglycolate regulates photosynthesis and starch accumulation in Arabidopsis. Plant Cell 29, 2537-2551. doi: 10.1105/tpc.17.00256

Fontaine, J. X., Ravel, C., Pageau, K., Heumez, E., Dubois, F., Hirel, B., et al. (2009). A quantitative genetic study for elucidating the contribution of glutamine synthetase, glutamate dehydrogenase and other nitrogen-related physiological traits to the agronomic performance of common wheat. Theor. Appl. Genet. 119, 645-662. doi: 10.1007/s00122-009-1076-4 
Fontaine, J. X., Terce-Laforgue, T., Armengaud, P., Clement, G., Renou, J. P., Pelletier, S., et al. (2012). Characterization of a NADH-dependent glutamate dehydrogenase mutant of Arabidopsis demonstrates the key role of this enzyme in root carbon and nitrogen metabolism. Plant Cell 24, 4044-4065. doi: $10.1105 /$ tpc.112.103689

Fuentes, S. I., Allen, D. J., Ortiz-Lopez, A., and Hernandez, G. (2001). Overexpression of cytosolic glutamine synthetase increases photosynthesis and growth at low nitrogen concentrations. J. Exp. Bot. 52, 1071-1081. doi: 10.1093/jexbot/52.358.1071

Gao, Y., de Bang, T. C., and Schjoerring, J. K. (2019). Cisgenic overexpression of cytosolic glutamine synthetase improves nitrogen utilization efficiency in barley and prevents grain protein decline under elevated $\mathrm{CO}_{2}$. Plant Biotechnol. J. 17, 1209-1221. doi: 10.1111/pbi.13046

Gaufichon, L., Marmagne, A., Belcram, K., Yoneyama, T., Sakakibara, Y., Hase, T., et al. (2017). ASN1-encoded asparagine synthetase in floral organs contributes to nitrogen filling in Arabidopsis seeds. Plant J. 91, 371-393. doi: 10.1111/ tpj. 13567

Gaufichon, L., Masclaux-Daubresse, C., Tcherkez, G., Reisdorf-Cren, M., Sakakibara, Y., Hase, T., et al. (2013). Arabidopsis thaliana ASN2 encoding asparagine synthetase is involved in the control of nitrogen assimilation and export during vegetative growth. Plant Cell Environ. 36, 328-342. doi: 10.1111/j.1365-3040.2012.02576.x

Gaufichon, L., Rothstein, S. J., and Suzuki, A. (2016). Asparagine metabolic pathways in Arabidopsis. Plant Cell Physiol. 57, 675-689. doi: 10.1093/pcp/ pcr184

Giannino, D., Nicolodi, C., Testone, G., Frugis, G., Pace, E., Santamaria, P., et al. (2007). The overexpression of asparagine synthetase A from E. coli affects the nitrogen status in leaves of lettuce (Lactuca sativa L.) and enhances vegetative growth. Euphytica 162, 11-22. doi: 10.1007/s10681-007-9506-3

Good, A. G., Johnson, S. J., De Pauw, M., Carroll, R. T., Savidov, N., Vidmar, J., et al. (2007). Engineering nitrogen use efficiency with alanine aminotransferase. Can. J. Bot. 85, 252-262. doi: 10.1139/B07-019

Guo, N., Hu, J., Yan, M., Qu, H., Luo, L., Tegeder, M., et al. (2020). Oryza sativa lysine-Histidine-type transporter 1 functions in root uptake and root-to-shoot allocation of amino acids in rice. Plant J. 103, 395-411. doi: 10.1111/tpj.14742

Han, M., Okamoto, M., Beatty, P. H., Rothstein, S. J., and Good, A. G. (2015). The genetics of nitrogen use efficiency in crop plants. Annu. Rev. Genet. 49, 269-289. doi: 10.1146/annurev-genet-112414-055037

Have, M., Marmagne, A., Chardon, F., and Masclaux-Daubresse, C. (2017). Nitrogen remobilization during leaf senescence: lessons from Arabidopsis to crops. J. Exp. Bot. 68, 2513-2529. doi: 10.1093/jxb/erw365

Hildebrandt, T. M. (2018). Synthesis versus degradation: directions of amino acid metabolism during Arabidopsis abiotic stress response. Plant Mol. Biol. 98, 121-135. doi: 10.1007/s11103-018-0767-0

Hildebrandt, T. M., Nunes Nesi, A., Araujo, W. L., and Braun, H. P. (2015). Amino acid catabolism in plants. Mol. Plant 8, 1563-1579. doi: 10.1016/j. molp.2015.09.005

Hirner, A., Ladwig, F., Stransky, H., Okumoto, S., Keinath, M., Harms, A., et al. (2006). Arabidopsis LHT1 is a high-affinity transporter for cellular amino acid uptake in both root epidermis and leaf mesophyll. Plant Cell 18, 1931-1946. doi: 10.1105/tpc.106.041012

Hodges, M., Dellero, Y., Keech, O., Betti, M., Raghavendra, A. S., Sage, R., et al. (2016). Perspectives for a better understanding of the metabolic integration of photorespiration within a complex plant primary metabolism network. J. Exp. Bot. 67, 3015-3026. doi: 10.1093/jxb/erw145

Hunt, E., Gattolin, S., Newbury, H. J., Bale, J. S., Tseng, H. M., Barrett, D. A., et al. (2010). A mutation in amino acid permease AAP6 reduces the amino acid content of the Arabidopsis sieve elements but leaves aphid herbivores unaffected. J. Exp. Bot. 61, 55-64. doi: 10.1093/jxb/erp274

Igarashi, D., Izumi, Y., Dokiya, Y., Totsuka, K., Fukusaki, E., and Ohsumi, C. (2009). Reproductive organs regulate leaf nitrogen metabolism mediated by cytokinin signal. Planta 229, 633-644. doi: 10.1007/s00425-008-0858-2

Igarashi, D., Tsuchida, H., Miyao, M., and Ohsumi, C. (2006). Glutamate:glyoxylate aminotransferase modulates amino acid content during photorespiration. Plant Physiol. 142, 901-910. doi: 10.1104/pp.106.085514

James, D., Borphukan, B., Fartyal, D., Ram, B., Singh, J., Manna, M., et al. (2018). Concurrent overexpression of OsGS1;1 and OsGS2 genes in transgenic Rice (Oryza sativa L.): impact on tolerance to abiotic stresses. Front. Plant Sci. 9:786. doi: 10.3389/fpls.2018.00786
Ji, Y., Huang, W., Wu, B., Fang, Z., and Wang, X. (2020). The amino acid transporter OsAAP1 mediates growth and grain yield by regulating neutral amino acids uptake and reallocation in Oryza sativa. J. Exp. Bot. 71, 4763-4777. doi: $10.1093 /$ jxb/eraa256

Kant, S., Bi, Y. M., and Rothstein, S. J. (2011). Understanding plant response to nitrogen limitation for the improvement of crop nitrogen use efficiency. J. Exp. Bot. 62, 1499-1509. doi: 10.1093/jxb/erq297

Koch, W., Kwart, M., Laubner, M., Heineke, D., Stransky, H., Frommer, W. B., et al. (2003). Reduced amino acid content in transgenic potato tubers due to antisense inhibition of the leaf $\mathrm{Hp} / \mathrm{amino}$ acid symporter StAAP1. Plant J. 33, 211-220. doi: 10.1046/j.1365-313x.2003.01618.x

Ladwig, F., Stahl, M., Ludewig, U., Hirner, A. A., Hammes, U. Z., Stadler, R., et al. (2012). Siliques are Red 1 from Arabidopsis acts as a bidirectional amino acid transporter that is crucial for the amino acid homeostasis of siliques. Plant Physiol. 158, 1643-1655. doi: 10.1104/pp.111.192583

Lam, H. M., Wong, P., Chan, H. K., Yam, K. M., Chen, L., Chow, C. M., et al. (2003). Overexpression of the ASN1 gene enhances nitrogen status in seeds of Arabidopsis. Plant Physiol. 132, 926-935. doi: 10.1104/pp.103.020123

Launay, A., Cabassa-Hourton, C., Eubel, H., Maldiney, R., Guivarc'h, A., Crilat, E., et al. (2019). Proline oxidation fuels mitochondrial respiration during darkinduced leaf senescence in Arabidopsis thaliana. J. Exp. Bot. 70, 6203-6214. doi: 10.1093/jxb/erz351

Law, S. R., Chrobok, D., Juvany, M., Delhomme, N., Linden, P., Brouwer, B., et al. (2018). Darkened leaves use different metabolic strategies for senescence and survival. Plant Physiol. 177, 132-150. doi: 10.1104/pp.18.00062

Lee, Y. H., Foster, J., Chen, J., Voll, L. M., Weber, A. P., and Tegeder, M. (2007). AAP1 transports uncharged amino acids into roots of Arabidopsis. Plant J. 50, 305-319. doi: 10.1111/j.1365-313X.2007.03045.x

Lee, S., Marmagne, A., Park, J., Fabien, C., Yim, Y., Kim, S. J., et al. (2020a). Concurrent activation of OsAMT1;2 and OsGOGAT1 in rice leads to enhanced nitrogen use efficiency under nitrogen limitation. Plant J. 103, 7-20. doi: $10.1111 /$ tpj.14794

Lee, S., Park, J., Lee, J., Shin, D., Marmagne, A., Lim, P. O., et al. (2020b). OsASN1 overexpression in Rice increases grain protein content and yield under nitrogen-limiting conditions. Plant Cell Physiol. 61, 1309-1320. doi: $10.1093 /$ pcp/pcaa060

Lehmann, S., Gumy, C., Blatter, E., Boeffel, S., Fricke, W., and Rentsch, D. (2011). In planta function of compatible solute transporters of the AtProT family. J. Exp. Bot. 62, 787-796. doi: 10.1093/jxb/erq320

Li, H. M., Liang, H., Li, Z., Tang, Z. X., Fu, S. L., Geng, Y. Y., et al. (2015). Dynamic QTL analysis of protein content and glutamine synthetase activity in recombinant inbred wheat lines. Genet. Mol. Res. 14, 8706-8715. doi: 10.4238/2015.July.31.19

Lightfoot, D. A., Mungur, R., Ameziane, R., Nolte, S., Long, L., Bernhard, K., et al. (2007). Improved drought tolerance of transgenic Zea mays plants that express the glutamate dehydrogenase gene (gdhA) of E. coli. Euphytica 156, 103-116. doi: 10.1007/s10681-007-9357-y

Liu, S., Wang, D., Mei, Y., Xia, T., Xu, W., Zhang, Y., et al. (2020). Overexpression of GmAAP6a enhances tolerance to low nitrogen and improves seed nitrogen status by optimizing amino acid partitioning in soybean. Plant Biotechnol. J. 18, 1749-1762. doi: 10.1111/pbi.13338

Lopez-Calcagno, P. E., Fisk, S., Brown, K. L., Bull, S. E., South, P. F., and Raines, C. A. (2019). Overexpressing the H-protein of the glycine cleavage system increases biomass yield in glasshouse and field-grown transgenic tobacco plants. Plant Biotechnol. J. 17, 141-151. doi: 10.1111/pbi.12953

Lothier, J., Gaufichon, L., Sormani, R., Lemaitre, T., Azzopardi, M., Morin, H., et al. (2011). The cytosolic glutamine synthetase GLN1;2 plays a role in the control of plant growth and ammonium homeostasis in Arabidopsis rosettes when nitrate supply is not limiting. J. Exp. Bot. 62, 1375-1390. doi: $10.1093 /$ jxb/erq299

Lu, T., Liu, L., Wei, M., Liu, Y., Qu, Z., Yang, C., et al. (2018b). The effect of poplar PsnGS1.2 overexpression on growth, secondary cell wall, and fiber characteristics in tobacco. Front. Plant Sci. 9:9. doi: 10.3389/fpls.2018.00009

Lu, K., Wu, B., Wang, J., Zhu, W., Nie, H., Qian, J., et al. (2018a). Blocking amino acid transporter OsAAP3 improves grain yield by promoting outgrowth buds and increasing tiller number in rice. Plant Biotechnol. J. 16, 1710-1722. doi: $10.1111 /$ pbi.12907

Ma, H., Cao, X., Shi, S., Li, S., Gao, J., Ma, Y., et al. (2016). Genome-wide survey and expression analysis of the amino acid transporter superfamily 
in potato (Solanum tuberosum L.). Plant Physiol. Biochem. 107, 164-177. doi: $10.1016 /$ j.plaphy.2016.06.007

Martin, A., Lee, J., Kichey, T., Gerentes, D., Zivy, M., Tatout, C., et al. (2006). Two cytosolic glutamine synthetase isoforms of maize are specifically involved in the control of grain production. Plant Cell 18, 3252-3274. doi: 10.1105/ tpc. 106.042689

Martinez-Andujar, C., Ghanem, M. E., Albacete, A., and Perez-Alfocea, F. (2013). Response to nitrate/ammonium nutrition of tomato (Solanum lycopersicum L.) plants overexpressing a prokaryotic $\mathrm{NH} 4(+)$-dependent asparagine synthetase. J. Plant Physiol. 170, 676-687. doi: 10.1016/j.jplph.2012.12.011

Masclaux-Daubresse, C., Chen, Q., and Have, M. (2017). Regulation of nutrient recycling via autophagy. Curr. Opin. Plant Biol. 39, 8-17. doi: 10.1016/j. pbi.2017.05.001

Masclaux-Daubresse, C., Daniel-Vedele, F., Dechorgnat, J., Chardon, F., Gaufichon, L., and Suzuki, A. (2010). Nitrogen uptake, assimilation and remobilization in plants: challenges for sustainable and productive agriculture. Ann. Bot. 105, 1141-1157. doi: 10.1093/aob/mcq028

Masclaux-Daubresse, C., Reisdorf-Cren, M., Pageau, K., Lelandais, M., Grandjean, O., Kronenberger, J., et al. (2006). Glutamine synthetase-glutamate synthase pathway and glutamate dehydrogenase play distinct roles in the sink-source nitrogen cycle in tobacco. Plant Physiol. 140, 444-456. doi: 10.1104/pp.105.071910

Maurino, V. G. (2019). Using energy-efficient synthetic biochemical pathways to bypass photorespiration. Biochem. Soc. Trans. 47, 1805-1813. doi: 10.1042/ BST20190322

McAllister, C. H., Beatty, P. H., and Good, A. G. (2012). Engineering nitrogen use efficient crop plants: the current status. Plant Biotechnol. J. 10, 1011-1025. doi: $10.1111 /$ j.1467-7652.2012.00700.x

McAllister, C. H., and Good, A. G. (2015). Alanine aminotransferase variants conferring diverse NUE phenotypes in Arabidopsis thaliana. PLoS One 10:e0121830. doi: 10.1371/journal.pone.0121830

Miyashita, Y., Dolferus, R., Ismond, K. P., and Good, A. G. (2007). Alanine aminotransferase catalyses the breakdown of alanine after hypoxia in Arabidopsis thaliana. Plant J. 49, 1108-1121. doi: 10.1111/j.1365-313X.2006.03023.x

Miyashita, Y., and Good, A. G. (2008). NAD(H)-dependent glutamate dehydrogenase is essential for the survival of Arabidopsis thaliana during dark-induced carbon starvation. J. Exp. Bot. 59, 667-680. doi: 10.1093/jxb/erm340

Modde, K., Timm, S., Florian, A., Michl, K., Fernie, A. R., and Bauwe, H. (2017). High serine:glyoxylate aminotransferase activity lowers leaf daytime serine levels, inducing the phosphoserine pathway in Arabidopsis. J. Exp. Bot. 68, 643-656. doi: 10.1093/jxb/erw467

Moison, M., Marmagne, A., Dinant, S., Soulay, F., Azzopardi, M., Lothier, J., et al. (2018). Three cytosolic glutamine synthetase isoforms localized in different-order veins act together for $\mathrm{N}$ remobilization and seed filling in Arabidopsis. J. Exp. Bot. 69, 4379-4393. doi: 10.1093/jxb/ery217

Muller, B., Fastner, A., Karmann, J., Mansch, V., Hoffmann, T., Schwab, W., et al. (2015). Amino acid export in developing Arabidopsis seeds depends on UmamiT facilitators. Curr. Biol. 25, 3126-3131. doi: 10.1016/j.cub.2015.10.038

Nielsen, K., and Schjoerring, J. K. (1998). Regulation of Apoplastic NH4 h concentration in leaves of oilseed rape. Plant Physiol. 118, 1361-1368. doi: 10.1104/pp.118.4.1361

Okumoto, S., Koch, W., Tegeder, M., Fischer, W. N., Biehl, A., Leister, D., et al. (2004). Root phloem-specific expression of the plasma membrane amino acid proton co-transporter AAP3. J. Exp. Bot. 55, 2155-2168. doi: $10.1093 /$ jxb/erh233

Oliveira, I. C., Brears, T., Knight, T. J., Clark, A., and Coruzzi, G. M. (2002). Overexpression of cytosolic glutamine synthetase. Relation to nitrogen, light, and photorespiration. Plant Physiol. 129, 1170-1180. doi: 10.1104/pp.020013

Ortega, J. L., Temple, S. J., Bagga, S., Ghoshroy, S., and Sengupta-Gopalan, C. (2004). Biochemical and molecular characterization of transgenic Lotus japonicus plants constitutively over-expressing a cytosolic glutamine synthetase gene. Planta 219, 807-818. doi: 10.1007/s00425-004-1292-8

Pena, P. A., Quach, T., Sato, S., Ge, Z., Nersesian, N., Dweikat, I. M., et al. (2017). Molecular and phenotypic characterization of transgenic wheat and sorghum events expressing the barley alanine aminotransferase. Planta 246, 1097-1107. doi: 10.1007/s00425-017-2753-1

Peng, B., Kong, H., Li, Y., Wang, L., Zhong, M., Sun, L., et al. (2014). OsAAP6 functions as an important regulator of grain protein content and nutritional quality in rice. Nat. Commun. 5:4847. doi: 10.1038/ncomms5847
Perchlik, M., Foster, J., and Tegeder, M. (2014). Different and overlapping functions of Arabidopsis LHT6 and AAP1 transporters in root amino acid uptake. J. Exp. Bot. 65, 5193-5204. doi: 10.1093/jxb/eru278

Perchlik, M., and Tegeder, M. (2017). Improving plant nitrogen use efficiency through alteration of amino acid transport processes. Plant Physiol. 175, 235-247. doi: 10.1104/pp.17.00608

Purnell, M. P., Skopelitis, D. S., Roubelakis-Angelakis, K. A., and Botella, J. R. (2005). Modulation of higher-plant $\mathrm{NAD}(\mathrm{H})$-dependent glutamate dehydrogenase activity in transgenic tobacco via alteration of beta subunit levels. Planta 222, 167-180. doi: 10.1007/s00425-005-1510-Z

Qu, Y., Ling, L., Wang, D., Zhang, T., and Guo, C. (2019). Genome-wide identification and expression analysis of the AAAP family in Medicago truncatula. Genetica 147, 185-196. doi: 10.1007/s10709-019-00062-6

Rennie, E. A., and Turgeon, R. (2009). A comprehensive picture of phloem loading strategies. Proc. Natl. Acad. Sci. U.S. A. 106, 14162-14167. doi: 10.1073/pnas.0902279106

Ricoult, C., Echeverria, L. O., Cliquet, J. B., and Limami, A. M. (2006). Characterization of alanine aminotransferase (AlaAT) multigene family and hypoxic response in young seedlings of the model legume Medicago truncatula. J. Exp. Bot. 57, 3079-3089. doi: 10.1093/jxb/erl069

Rolletschek, H., Hosein, F., Miranda, M., Heim, U., Gotz, K. P., Schlereth, A., et al. (2005). Ectopic expression of an amino acid transporter (VfAAP1) in seeds of Vicia narbonensis and pea increases storage proteins. Plant Physiol. 137, 1236-1249. doi: 10.1104/pp.104.056523

Salon, C., Avice, J. C., Colombie, S., Dieuaide-Noubhani, M., Gallardo, K., Jeudy, C., et al. (2017). Fluxomics links cellular functional analyses to wholeplant phenotyping. J. Exp. Bot. 68, 2083-2098. doi: 10.1093/jxb/erx126

Santiago, J. P., and Tegeder, M. (2016). Connecting source with sink: the role of Arabidopsis AAP8 in phloem loading of amino acids. Plant Physiol. 171, 508-521. doi: 10.1104/pp.16.00244

Santiago, J. P., and Tegeder, M. (2017). Implications of nitrogen phloem loading for carbon metabolism and transport during Arabidopsis development. J. Integr. Plant Biol. 59, 409-421. doi: 10.1111/jipb.12533

Seger, M., Gebril, S., Tabilona, J., Peel, A., and Sengupta-Gopalan, C. (2015). Impact of concurrent overexpression of cytosolic glutamine synthetase (GS1) and sucrose phosphate synthase (SPS) on growth and development in transgenic tobacco. Planta 241, 69-81. doi: 10.1007/s00425-014-2165-4

Seiffert, B., Zhou, Z., Wallbraun, M., Lohaus, G., and Mollers, C. (2004). Expression of a bacterial asparagine synthetase gene in oilseed rape (Brassica napus) and its effect on traits related to nitrogen efficiency. Physiol. Plant. 121, 656-665. doi: 10.1111/j.1399-3054.2004.00361.x

Shrawat, A. K., Carroll, R. T., DePauw, M., Taylor, G. J., and Good, A. G. (2008). Genetic engineering of improved nitrogen use efficiency in rice by the tissue-specific expression of alanine aminotransferase. Plant Biotechnol. J. 6, 722-732. doi: 10.1111/j.1467-7652.2008.00351.x

Silva, I. T., Abbaraju, H. K. R., Fallis, L. P., Liu, H., Lee, M., and Dhugga, K. S. (2018). Biochemical and genetic analyses of $\mathrm{N}$ metabolism in maize testcross seedlings: 2. Roots. Theor. Appl. Genet. 131, 1191-1205. doi: 10.1007/s00122-018-3071-0

Sisharmini, A., Apriana, A., Khumaida, N., Trijatmiko, K. R., and Purwoko, B. S. (2019). Expression of a cucumber alanine aminotransferase 2 gene improves nitrogen use efficiency in transgenic rice. J. Genet. Eng. Biotechnol. 17:9. doi: 10.1186/s43141-019-0010-7

Skopelitis, D. S., Paranychianakis, N. V., Paschalidis, K. A., Pliakonis, E. D., Delis, I. D., Yakoumakis, D. I., et al. (2006). Abiotic stress generates ROS that signal expression of anionic glutamate dehydrogenases to form glutamate for proline synthesis in tobacco and grapevine. Plant Cell 18, 2767-2781. doi: $10.1105 /$ tpc. 105.038323

Snyman, S. J., Hajari, E., Watt, M. P., Lu, Y., and Kridl, J. C. (2015). Improved nitrogen use efficiency in transgenic sugarcane: phenotypic assessment in a pot trial under low nitrogen conditions. Plant Cell Rep. 34, 667-669. doi: 10.1007/s00299-015-1768-y

Somerville, C., and Ogren, W. (1980). Photorespiration mutants of Arabidopsis thaliana deficient in serine-glyoxylate aminotransferase activity. Proc. Natl. Acad. Sci. U. S. A. 77, 2684-2687. doi: 10.1073/pnas.77.5.2684

Sonnewald, U., and Fernie, A. R. (2018). Next-generation strategies for understanding and influencing source-sink relations in crop plants. Curr. Opin. Plant Biol. 43, 63-70. doi: 10.1016/j.pbi.2018.01.004

Su, Y. H., Frommer, W. B., and Ludewig, U. (2004). Molecular and functional characterization of a family of amino acid transporters from Arabidopsis. Plant Physiol. 136, 3104-3113. doi: 10.1104/pp.104.045278 
Suzuki, A., and Knaff, D. B. (2005). Glutamate synthase: structural, mechanistic and regulatory properties, and role in the amino acid metabolism. Photosynth. Res. 83, 191-217. doi: 10.1007/s11120-004-3478-0

Svennerstam, H., Ganeteg, U., Bellini, C., and Nasholm, T. (2007). Comprehensive screening of Arabidopsis mutants suggests the lysine histidine transporter 1 to be involved in plant uptake of amino acids. Plant Physiol. 143, 1853-1860. doi: 10.1104/pp.106.092205

Svennerstam, H., Jamtgard, S., Ahmad, I., Huss-Danell, K., Nasholm, T., and Ganeteg, U. (2011). Transporters in Arabidopsis roots mediating uptake of amino acids at naturally occurring concentrations. New Phytol. 191, 459-467. doi: $10.1111 /$ j.1469-8137.2011.03699.x

Tegeder, M., and Masclaux-Daubresse, C. (2018). Source and sink mechanisms of nitrogen transport and use. New Phytol. 217, 35-53. doi: 10.1111/nph.14876

Tegeder, M., and Ward, J. M. (2012). Molecular evolution of plant AAP and LHT amino acid transporters. Front. Plant Sci. 3:21. doi: 10.3389/fpls.2012.00021

Terce-Laforgue, T., Bedu, M., Dargel-Grafin, C., Dubois, F., Gibon, Y., Restivo, F. M., et al. (2013). Resolving the role of plant glutamate dehydrogenase: II. Physiological characterization of plants overexpressing the two enzyme subunits individually or simultaneously. Plant Cell Physiol. 54, 1635-1647. doi: $10.1093 / \mathrm{pcp} / \mathrm{pct} 108$

Terce-Laforgue, T., Clement, G., Marchi, L., Restivo, F. M., Lea, P. J., and Hirel, B. (2015). Resolving the role of plant NAD-glutamate dehydrogenase: III. Overexpressing individually or simultaneously the two enzyme subunits under salt stress induces changes in the leaf metabolic profile and increases plant biomass production. Plant Cell Physiol. 56, 1918-1929. doi: 10.1093/ pcp/pcv114

Thomsen, H. C., Eriksson, D., Moller, I. S., and Schjoerring, J. K. (2014). Cytosolic glutamine synthetase: a target for improvement of crop nitrogen use efficiency? Trends Plant Sci. 19, 656-663. doi: 10.1016/j.tplants.2014.06.002

Timm, S., Florian, A., Arrivault, S., Stitt, M., Fernie, A. R., and Bauwe, H. (2012). Glycine decarboxylase controls photosynthesis and plant growth. FEBS Lett. 586, 3692-3697. doi: 10.1016/j.febslet.2012.08.027

Timm, S., and Hagemann, M. (2020). Photorespiration - how is it regulated and regulates overall plant metabolism? J. Exp. Bot. 71, 3955-3965. doi: $10.1093 /$ jxb/eraa 183

Timm, S., Wittmiss, M., Gamlien, S., Ewald, R., Florian, A., Frank, M., et al. (2015). Mitochondrial Dihydrolipoyl dehydrogenase activity shapes photosynthesis and photorespiration of Arabidopsis thaliana. Plant Cell 27, 1968-1984. doi: 10.1105/tpc.15.00105

Timm, S., Woitschach, F., Heise, C., Hagemann, M., and Bauwe, H. (2019). Faster removal of 2-phosphoglycolate through photorespiration improves abiotic stress tolerance of Arabidopsis. Plants 8:563. doi: 10.3390/plants8120563

Urriola, J., and Rathore, K. S. (2015). Overexpression of a glutamine synthetase gene affects growth and development in sorghum. Transgenic Res. 24, 397-407. doi: 10.1007/s11248-014-9852-6

Voll, L. M., Jamai, A., Renne, P., Voll, H., McClung, C. R., and Weber, A. P. (2006). The photorespiratory Arabidopsis shm 1 mutant is deficient in SHM1. Plant Physiol. 140, 59-66. doi: 10.1104/pp.105.071399

Wallsgrove, R., Turner, J., Hall, N., Kendall, A., and Bright, S. (1987). Barley mutants lacking chloroplast glutamine Synthetase-biochemical and genetic analysis. Plant Physiol. 83, 155-158. doi: 10.1104/pp.83.1.155

Wan, Y., King, R., Mitchell, R. A. C., Hassani-Pak, K., and Hawkesford, M. J. (2017). Spatiotemporal expression patterns of wheat amino acid transporters reveal their putative roles in nitrogen transport and responses to abiotic stress. Sci. Rep. 7:5461. doi: 10.1038/s41598-017-04473-3

Wang, T., Chen, Y., Zhang, M., Chen, J., Liu, J., Han, H., et al. (2017). Arabidopsis AMINO ACID PERMEASE1 contributes to salt stress-induced Proline uptake from exogenous sources. Front. Plant Sci. 8:2182. doi: 10.3389/fpls.2017.02182

Wang, M., Toda, K., Block, A., and Maeda, H. A. (2019b). TAT1 and TAT2 tyrosine aminotransferases have both distinct and shared functions in tyrosine metabolism and degradation in Arabidopsis thaliana. J. Biol. Chem. 294, 3563-3576. doi: 10.1074/jbc.RA118.006539

Wang, J., Wu, B., Lu, K., Wei, Q., Qian, J., Chen, Y., et al. (2019a). The amino acid Permease 5 (OsAAP5) regulates tiller number and grain yield in Rice. Plant Physiol. 180, 1031-1045. doi: 10.1104/pp.19.00034

Wang, X., Yang, G., Shi, M., Hao, D., Wei, Q., Wang, Z., et al. (2019c). Disruption of an amino acid transporter LHT1 leads to growth inhibition and low yields in rice. BMC Plant Biol. 19:268. doi: 10.1186/s12870-019-1885-9

Ward, M. H., Jones, R. R., Brender, J. D., de Kok, T. M., Weyer, P. J., Nolan, B. T., et al. (2018). Drinking water nitrate and human health: An updated review. Int. J. Environ. Res. Public Health 15:1557. doi: 10.3390/ijerph15071557

Wu, J., Zhang, Z., Zhang, Q., Han, X., Gu, X., and Lu, T. (2015). The molecular cloning and clarification of a photorespiratory mutant, oscdm1, using enhancer trapping. Front. Genet. 6:226. doi: 10.3389/fgene.2015.00226

Xu, G., Fan, X., and Miller, A. J. (2012). Plant nitrogen assimilation and use efficiency. Annu. Rev. Plant Biol. 63, 153-182. doi: 10.1146/annurevarplant-042811-105532

Yamaya, T., Obara, M., Nakajima, H., Sasaki, S., Hayakawa, T., and Sato, T. (2002). Genetic manipulation and quantitative-trait loci mapping for nitrogen recycling in rice. J. Exp. Bot. 53, 917-925. doi: 10.1093/jexbot/53.370.917

Yoneyama, T., and Suzuki, A. (2019). Exploration of nitrate-to-glutamate assimilation in non-photosynthetic roots of higher plants by studies of (15) $\mathrm{N}$-tracing, enzymes involved, reductant supply, and nitrate signaling: a review and synthesis. Plant Physiol. Biochem. 136, 245-254. doi: 10.1016/j. plaphy.2018.12.011

Yu, H., Zhang, Y., Zhang, Z., Zhang, J., Wei, Y., Jia, X., et al. (2020). Towards identification of molecular mechanism in which the overexpression of wheat cytosolic and plastid glutamine synthetases in tobacco enhanced drought tolerance. Plant Physiol. Biochem. 151, 608-620. doi: 10.1016/j.plaphy.2020.04.013

Zhang, X., Davidson, E. A., Mauzerall, D. L., Searchinger, T. D., Dumas, P., and Shen, Y. (2015). Managing nitrogen for sustainable development. Nature 528, 51-59. doi: 10.1038/nature 15743

Zhang, L., Tan, Q., Lee, R., Trethewy, A., Lee, Y. H., and Tegeder, M. (2010). Altered xylem-phloem transfer of amino acids affects metabolism and leads to increased seed yield and oil content in Arabidopsis. Plant Cell 22, 3603-3620. doi: 10.1105/tpc.110.073833

Zhou, Y., Liu, H., Zhou, X., Yan, Y., Du, C., Li, Y., et al. (2014). Over-expression of a fungal NADP(H)-dependent glutamate dehydrogenase PcGDH improves nitrogen assimilation and growth quality in rice. Mol. Breed. 34, 335-349. doi: $10.1007 /$ s11032-014-0037-Z

Zhou, T., Yue, C. P., Huang, J. Y., Cui, J. Q., Liu, Y., Wang, W. M., et al. (2020). Genome-wide identification of the amino acid permease genes and molecular characterization of their transcriptional responses to various nutrient stresses in allotetraploid rapeseed. BMC Plant Biol. 20:151. doi: 10.1186/s12870-020-02367-7

Zhou, Y., Zhang, C., Lin, J., Yang, Y., Peng, Y., Tang, D., et al. (2015). Overexpression of a glutamate dehydrogenase gene, $\mathrm{MgGDH}$, from Magnaporthe grisea confers tolerance to dehydration stress in transgenic rice. Planta 241, 727-740. doi: 10.1007/s00425-014-2214-Z

Conflict of Interest: The author declares that the research was conducted in the absence of any commercial or financial relationships that could be construed as a potential conflict of interest.

Copyright (c) 2020 Dellero. This is an open-access article distributed under the terms of the Creative Commons Attribution License (CC BY). The use, distribution or reproduction in other forums is permitted, provided the original author(s) and the copyright owner(s) are credited and that the original publication in this journal is cited, in accordance with accepted academic practice. No use, distribution or reproduction is permitted which does not comply with these terms. 